\title{
Mode II Fracture of GFRP Laminates Bonded Interfaces under 4-ENF Test
}

\author{
Zhi-peng Zhong ${ }^{1,2}$ and Hong Liu ${ }^{1}$ \\ ${ }^{1}$ Department of Civil Engineering, Shanxi University, Taiyuan, Shanxi 030013, China \\ ${ }^{2}$ Key Laboratory of C\&PC Structures of the Ministry of Education, Southeast University, Nanjing 210096, China
}

Correspondence should be addressed to Hong Liu; liuhong1966@sxu.edu.cn

Received 24 December 2016; Revised 22 June 2017; Accepted 3 July 2017; Published 15 August 2017

Academic Editor: Katsuyuki Kida

Copyright ( 2017 Zhi-peng Zhong and Hong Liu. This is an open access article distributed under the Creative Commons Attribution License, which permits unrestricted use, distribution, and reproduction in any medium, provided the original work is properly cited.

\begin{abstract}
This experiment studies the mode II fracture behavior of an adhesively bonded joint composed of GFRP laminates. A new beam model is presented to calculate the mode II ERR for GFRP bonded 4-ENF specimens. In this model, the deformation of 4-ENF specimens caused by the relative deflection angle between the upper and lower layers and by the bending deformation of the upper and lower layers, respectively, is introduced; the effect of the adhesive layer deformation is presented. The closed-form analytical solutions of compliance and energy release rate based on the crack compliance method are obtained. The high accuracy of present analytical solutions are verified by finite element analysis through bonded GFRP 4-ENF specimens and compared to the rigid joint model and the CBT model. The interfacial crack propagation is numerically simulated using shear fracture toughness determined in this experiment, from which the predicted critical load results are in good agreement with the experimental results. The conclusion indicates that the compliance and ERR can accurately be predicted using the new bonded 4-ENF beam model.
\end{abstract}

\section{Introduction}

To combat problems associated with concrete/steel deck fatigue and corrosion, glass fiber-reinforced polymer (GFRP) bridge deck structures have been widely used in the bridge engineering field in recent years. Advantages of using GFRP include its light weight, high strength, and corrosion resistance $[1,2]$. A GFRP bridge panel system is comprised of modular tube form units integrated via adhesive bonding. The adhesively bonded interface usually transfers shear forces and allows the GFRP modular tubes to bear loads together. However, the adhesive bonding joints are the weak links in the entire structure. They can easily delaminate and crack due to overloading or fatigue. Therefore, the reliability of the adhesive bonding joints plays a key role in ensuring the integrity, and influences the structural behavior of GFRP bridge decks $[3,4]$. To design effective, reliable bonding joints, the accurate determination of shear fracture toughness of GFRP adhesively bonded joints under mode II loading is necessary.

Fracture toughness is the characterization of the bonding interface properties of GFRP. In the literature, there has been much study of fracture toughness [5-13]. However, it is the stable cracking problem that should be investigated in the interfacial debonding test. The end-notched flexure (ENF) test and the four-point bend end-notched flexure (4ENF) test have been commonly employed to determine the mode II bonding fracture toughness. The original ENF test is essentially unstable and requires to measure the crack sliding displacement of the specimen during the experimental process [5]. This test procedure is too complex to achieve accurate results. To avoid the disadvantages of the ENF test, a 4-ENF test was proposed by Martin and Davidson [6,7]. The 4-ENF test is stable and does not require measuring crack length during the experiment. What is more, there is only pure moment, and no shear force exists within the crack tip of the 4-ENF test, which reduces the frictional effect across the delaminated interface. Other alternatives for mode II fracture research are the end-loaded split (ELS) test [8-10] and the over notched flexure (ONF) test $[11,12]$. The ELS test raises stable crack propagation, but it contains large vertical deflection for thin specimens. The ONF test seems to be simple and also results in stable crack propagation, similar to the 4-ENF test [13]. 
To get accurate values for the mode II fracture toughness of materials, both theoretical and experimental fracture characteristic research have been conducted in past decades.

Russell and Street [14] performed a simple beam theory that neglected the crack tip singularity and the transverse shear deformation of the specimen, so the energy release rate (ERR) is significantly underestimated in their solution. Carlsson et al. [15] suggested Timoshenko's beam theory to obtain the flexibility and ERR of 4-ENF beams. However, there was some deviation from the result obtained by using finite element analysis. To get an accurate solution, several modifications have been provided in recent years. Whitney and Sun [16] proposed a higher order beam theory based on Reissner's Principle to analyze an ENF specimen. The shear deformation is considered and the shear singularity at the crack tip is omitted and regarded as the surface tensile stress in the higher order beam theory. Wang and Williams [17] derived an additional length of $v_{h}$ to the original crack length by introducing a correction factor $v$. Then the ERR was evaluated by the formulation of classical beam theory (CBT) using the adjusted crack length. Corleto and Hogan [5] employed two-parameter semi-infinite elastic foundation to the Timoshenko beam model to obtain the compliance and ERR of ENF specimens, in which the crack tip deformation was considered in their model. Ding and Kortschot [18] adapted a simplified analysis of a beam supported on a shear spring without accounting for the transverse shear deformation in order to find a simple and precise analytical solution. By using the superposition principle, Wang and Qiao [19] decomposed ENF into a three-point uncracked bending beam and an asymmetric cracked beam under shear action on the crack surface. The compliance and ERR of the ENF are obtained based on the compatibility of deformation.

Currently, most of the literature is confined to GFRP laminates delamination, and a method is developed that can predict delamination of GFRP laminates through analysis. In practice, however, in fiber-reinforced polymer (FRP) engineering structures, mode II crack growth is the common failure form of adhesive bonding joints for the bonding structure (e.g., GFRP bridge decks and FRP strengthening concrete structures) [20]. As there are some deviations (e.g., joint dimensions and failure modes) from the available results, it is necessary to study interfacial debonding behavior of adhesively bonded composite joints [21]. However, there is little research into the behavior of adhesively bonded joints composed of pultruded FRP laminates. It is necessary to study the mode II bond interface fracture toughness of adhesive joints. Therefore, research into the validity and practical formulas for determining mode II fracture toughness of FRP adhesive bonding joints is necessary.

This research is to understand the mode II fracture behavior of adhesive-bonded composite joints using pultruded GFRP 4-ENF specimens. To better represent the effect of adhesive layer stiffness on the deflection and ERR on GFRP 4-ENF specimens, a two-dimensional model based on adhesive layer deformable beam theory is used in this paper. The adherends are treated as a distinct deformation Euler-Bernoulli beam, and the adhesive layer is treated as Goodman's elastic interlayer. The longitudinal deformation of adherends is caused by the relative deflection angle between the upper and lower layers, the longitudinal displacement of the adherends, and the vertical displacement caused by the bending deformation of the upper and lower layers. The compatibility of deformation at the mid-plane of the bonding specimen is satisfied by incorporating deformation of the adhesive layer and bonding interface. Using a combination of the beam force balance equation and the adhesive constitutive equation, the theoretical calculation formula of deflection deformation of 4-ENF beams is derived. In addition, mode II ERR $G_{\text {II }}$ is calculated using the compliance method, which is compared with finite element analysis and existing literature results. Further, a 4-ENF test on GFRP bonded specimens was conducted to determine the critical energy release rate $G_{\text {IIc }}$ based on load versus displacement curves. Finally, an interfacial crack propagation process is simulated by the virtual crack closure technique (VCCT) applying existing $G_{\text {IIc }}$. The critical load for interfacial crack initiation also predicted by finite element analysis is validated by comparing the experimental results.

\section{Analysis of 4-ENF Specimens with an Adhesive Layer}

A typical 4-ENF specimen with an adhesive layer under loading of $P$ at the points of $x=L_{0}$ and $x=a+L_{1}$ by the left rollers can be modelled as a simply supported beam with a span of $L$ and an end traction free crack of length $a$ (Figure 1). In this paper, the 4-ENF test takes place under the symmetric loading, so the length $a+L_{1}=L-L_{0}$. The top beam and bottom beam have thicknesses of $h_{1}$ and $h_{2}$, respectively. The thickness of the adhesive layer is $h_{a}$ and the beam width is $b$. Considering that the span of $L$ is greater than the bonded beam thickness, transverse shear deformation is not incorporated.

Next, considering the uncracked region $(a<x<L)$ in Figure 1, the internal forces are expressed as a beam theory (Figure 2). $N_{i}, M_{i}$, and $Q_{i}(i=1,2)$ are defined as the internal axial forces, bending moments, and transverse shear forces in sublayers 1 and 2, respectively.

According to the internal forces and stresses shown in Figure 2, the equilibrium equations for an infinitesimal isolated body of two adherends are given by

$$
\begin{aligned}
& \frac{d N_{1}(x)}{d x}=b \tau(x), \\
& \frac{d Q_{1}(x)}{d x}=b \sigma(x) \\
& \frac{d N_{2}(x)}{d x}=-b \tau(x), \\
& \frac{d Q_{2}(x)}{d x}=-b \sigma(x) \\
& \frac{d M_{1}(x)}{d x}=Q_{1}(x)-b \tau(x) \frac{h_{1}}{2}, \\
& \frac{d M_{2}(x)}{d x}=Q_{2}(x)-b \tau(x) \frac{h_{2}}{2},
\end{aligned}
$$




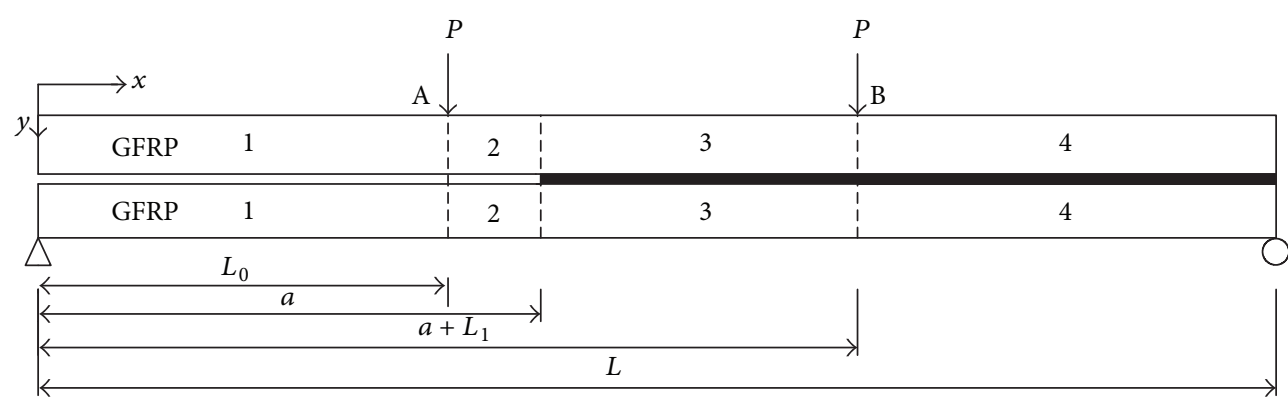

FIgURE 1: Configuration of the 4-ENF beam.

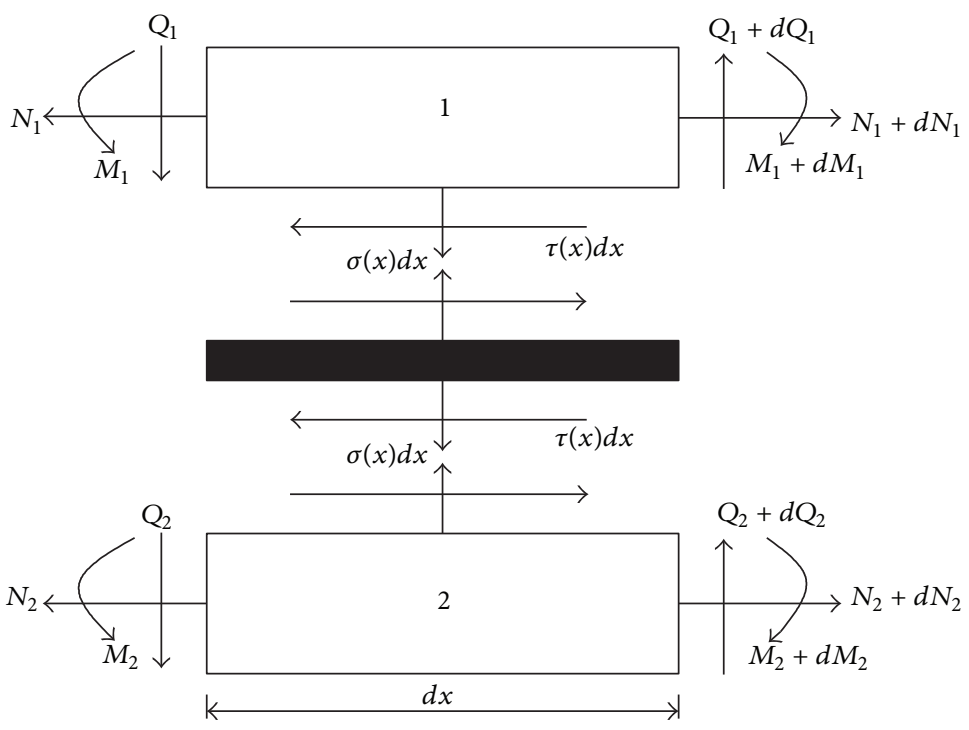

FIGURE 2: Infinitesimal isolated body diagram of sublayers.

where $\sigma(x)$ and $\tau(x)$ are the peel and shear stresses of the adhesive layer, respectively.

According to GFRP laminated beam theory, the relationship between the internal forces and displacement for two adherends can be described as follows:

$$
\begin{aligned}
& N_{i}=A_{i i} \frac{d u_{i}}{d x}+B_{i i} \frac{d \phi_{i}}{d x}, \\
& M_{i}=B_{i i} \frac{d u_{i}}{d x}+D_{i i} \frac{d \phi_{i}}{d x},
\end{aligned}
$$

where $u_{i}$ and $\phi_{i}$ are the $i$ th sublayer's longitudinal and rotation angle, respectively; $A_{i i}, B_{i i}$, and $D_{i i}$ are the $i$ th sublayer's tension stiffness, coupling stiffness, and flexural stiffness, respectively; $\left(A_{i i}, B_{i i}, D_{i i}\right)=b \int_{-h_{i} / 2}^{h_{i} / 2} Q_{i i}\left(1, z, z^{2}\right) d z$, where $Q_{i i}$ is the off-axis stiffness coefficient, and $i=1,2$ denotes sublayers 1 and 2 .

For the 4-ENF beam, the axial force on the bonded cross section is zero. The equilibrium conditions can be shown as follows:

$$
N_{T}(x)=N_{1}(x)+N_{2}(x)=0 \text {, }
$$

where $N_{T}(x)$ is the resultant axial internal force. From (5), we can obtain

$$
N_{1}(x)=-N_{2}(x)
$$

The shear force on the cross section is described as

$$
Q_{1}(x)+Q_{2}(x)+Q_{a}(x)=Q_{T}(x),
$$

where $Q_{T}(x)$ and $Q_{a}(x)$ are the resultant transverse shear force and the shear force of the adhesive.

The integral bending behavior of the 4-ENF beam can be considered as the superposition of the overall bending action and the bending action for the upper and lower layers, respectively.

$$
\begin{aligned}
& M_{t c}(x)=-N_{2} \frac{h_{2}+h_{a}}{2}+N_{1} \frac{h_{1}+h_{a}}{2} \\
& M_{12}(x)=M_{1}(x)+M_{2}(x) \\
& M_{T}(x)=M_{12}(x)+M_{t c}(x),
\end{aligned}
$$

where $M_{T}(x)$ is the resultant transverse moment of the cross section for the bonded beam. 
Taking the derivative of the 1st equation and 2 nd equation for (3) and adding the two equations, then combining with (4), the deflection differential equation is derived:

$$
E_{1} I_{1} \frac{d^{4} w_{1}}{d x^{4}}+E_{2} I_{2} \frac{d^{4} w_{2}}{d x^{4}}=b d_{3} \frac{d \tau(x)}{d x},
$$

where $d_{3}=\left(h_{1}+h_{2}+2 h_{a}\right) / 2$.

When the 4 -ENF beam is in linear elastic range, the longitudinal displacement is caused by the relative deflection angle between the upper and lower layers, the longitudinal displacement of the adherends, and the vertical displacement caused by the bending deformation of the upper and lower layers.

Based on the linear superposition principle, the lower surface displacement of the upper layer is

$$
u_{u}=u_{1}-\frac{h_{1}+h_{a}}{2} \phi+\frac{h_{1}}{2} \phi_{i} .
$$

The upper surface displacement of the lower layer is

$$
u_{l}=u_{2}+\frac{h_{1}+h_{a}}{2} \phi+\frac{h_{2}}{2} \phi_{i}
$$

where $\phi$ is the relative deflection angle between the upper and lower layers.

Combined with (10) and (11), the constitutive relation of the adhesive layer is expressed as follows:

$$
\begin{aligned}
& \tau(x)=\frac{G\left(u_{u}-u_{l}\right)}{h_{a}}=\frac{G}{h_{a}}\left(u_{1}-\frac{h_{1}+h_{a}}{2} \phi+\frac{h_{1}}{2} \phi_{i}\right. \\
& \left.-u_{2}-\frac{h_{1}+h_{a}}{2} \phi-\frac{h_{2}}{2} \phi_{i}\right) .
\end{aligned}
$$

Equation (12) by second derivative is reduced to

$$
\begin{aligned}
& \frac{d^{2} \tau(x)}{d x^{2}}=\frac{G}{h_{a}}\left(\left(\frac{1}{E_{1} A_{1}}+\frac{1}{E_{2} A_{2}}\right) \frac{d N_{1}}{d x}+\frac{h_{1}}{2} \frac{d^{3} w_{1}}{d x^{3}}\right. \\
& \left.+\frac{h_{2}}{2} \frac{d^{3} w_{2}}{d x^{3}}\right) .
\end{aligned}
$$

For the configuration of the 4-ENF specimen, the vertical extrusion can be ignored; that is, $w_{i}=w, d \phi / d x=$ $d \phi_{i} / d x=-d^{2} w_{i} / d x^{2}$. By differentiating (13) and combining this with (12), the deflection differential equation of the 4ENF specimen is obtained as

$$
\frac{d^{6} w}{d x^{6}}=\frac{G_{a}}{h_{a}}\left(\frac{b}{E_{1} A_{0}}+\frac{b d_{3}\left(h_{1} / 2+h_{2} / 2\right)}{\left(E_{1} I_{1}+E_{2} I_{2}\right)}\right) \frac{d^{4} w}{d x^{4}},
$$

where $1 / E_{1} A_{0}=1 / E_{1} A_{1}+1 / E_{2} A_{2}$.

Solving (14), the deflection of the 4 -ENF specimen is obtained as

$$
w=B_{1} e^{s x}+B_{2} e^{-s x}+B_{3} x^{3}+B_{4} x^{2}+B_{5} x+B_{6},
$$

where

$$
s=\sqrt{\frac{G_{a}}{h_{a}}\left(\frac{b}{E_{1} A_{0}}+\frac{b d_{3} h_{1}+b d_{3} h_{2}}{2\left(E_{1} I_{1}+E_{2} I_{2}\right)}\right)} .
$$

For crack area $1\left(0 \leq x \leq L_{0}\right)$, the bending moment of the upper layer is

$$
M_{1}(x)=\alpha P x,
$$

where $\alpha=D_{1} /\left(D_{1}+D_{2}\right), D_{1}$ and $D_{2}$ are the bending stiffness on upper and lower layer, respectively.

Substituting (15) and (17) into (4) yields

$$
w(x)=-\frac{\alpha P x^{3}}{6 D_{1}}+C_{1} x+C_{2} .
$$

For crack area $2\left(L_{0} \leq x \leq a\right)$, the bending moment of upper layer is

$$
M_{1}(x)=\alpha P L_{0}
$$

Substituting (18) and (19) into (4) yields

$$
w(x)=-\frac{\alpha P L_{0}}{2 D_{1}} x^{2}+C_{3} x+C_{4} .
$$

The boundary conditions and displacement compatibility for the 4-ENF specimen can be expressed as

$$
\begin{aligned}
\left.w\right|_{x=0} & =0, \\
\left.w\right|_{x=L} & =0, \\
\left.w\right|_{x=L_{0}^{-}} & =\left.w\right|_{x=L_{0}^{+}}, \\
\left.w^{\prime}\right|_{x=L_{0}^{-}} & =\left.w^{\prime}\right|_{x=L_{0}^{+}}, \\
\left.w\right|_{x=a^{-}} & =\left.w\right|_{x=a^{+}}, \\
\left.w^{\prime}\right|_{x=a^{-}} & =\left.w^{\prime}\right|_{x=a^{+}}, \\
\left.w^{\prime \prime}\right|_{x=a^{+}} & =-\frac{P L_{0}}{D}, \\
\left.w^{\prime \prime \prime}\right|_{x=a^{+}} & =0, \\
\left.w^{\prime \prime}\right|_{x=L^{-}} & =0, \\
\left.w^{\prime \prime \prime}\right|_{x=L^{-}} & =\frac{\alpha P}{D_{1}},
\end{aligned}
$$

where $D=b\left(h_{1}+h_{2}+h_{a}\right)^{3} / 12$. From (21), the ten unknown constants $B_{1}, B_{2}, B_{3}, B_{4}, B_{5}, B_{6}, C_{1}, C_{2}, C_{3}$, and $C_{4}$ can be obtained as detailed in Appendix, from which the vertical displacement $w$ of the 4-ENF beam can be determined.

From [19], the ERR from the 4-ENF test data is accurately calculated based on the compliance method:

$$
G_{\mathrm{II}}=\frac{P^{2}}{2 b} \frac{d C}{d a} .
$$

As mentioned in [22], the compliance calibration method is very suitable for the linear elastic loading configuration characterized by a single applied load and a single induced displacement. To realize the linear elastic loading configuration, the single applied load is deemed as the total load applied 
to the bonded beam, and the single induced displacement is deemed as the displacement at the center of the span [6]. Therefore, the compliance $C$ of the 4-ENF beam is defined as

$$
C=\frac{\bar{w}}{P_{T}}=\frac{w_{L}+w_{R}}{2\left(P_{L}+P_{R}\right)}=\frac{w_{L}+w_{R}}{4 P},
$$

where $P_{T}=2 P$ is the applied load, $\bar{w}$ is the displacement at the center of the span, $w_{L}$ and $w_{R}$ are the displacements at the left and right loading rollers, respectively, which can be obtained by the above-mentioned deflection formula as follows:

$$
\begin{aligned}
w_{L}= & -\frac{\alpha P L_{0}^{3}}{6 D_{1}}+C_{1} L_{0} \\
w_{R}= & B_{1} e^{s\left(L-L_{0}\right)}+B_{2} e^{-s\left(L-L_{0}\right)}+B_{3}\left(L-L_{0}\right)^{3} \\
& +B_{4}\left(L-L_{0}\right)^{2}+B_{5}\left(L-L_{0}\right)+B_{6} .
\end{aligned}
$$

By combining with (23) and (24), the compliance $C$ is determined as

$$
\begin{aligned}
C= & \frac{F_{0}}{24 D D_{1} s^{3}(s L-2)} \\
& +\frac{2 \alpha D L_{0}^{2} s-D_{1} L_{0}^{2} s-\alpha D L_{0}}{8 D D_{1} s} a,
\end{aligned}
$$

where $F_{0}$ is given in Appendix.

Then, by combining with (25), the energy release rate, $G_{\text {II }}$, is obtained as follows:

$$
G_{\text {II }}=\frac{P_{T}^{2}}{2 b} \frac{d C}{d a}=\frac{2 P^{2}}{b}\left(\frac{2 \alpha D L_{0}^{2} s-D_{1} L_{0}^{2} s-\alpha D L_{0}}{8 D D_{1} s}\right) .
$$

From (26), we can see that the fracture toughness can be directly obtained for each testing process by determining the critical load, from which the length of crack propagation is not measured. The critical load is determined by examining the typical load-displacement curve during the fracture experiment.

\section{Result Verification and Discussion}

To verify the accuracy of this model, the analytical results for $G_{\text {II }}$ of the GFRP bonded interface 4-ENF specimen are examined by comparison with a rigid joint model, conventional beam theory, and two-dimensional finite element analysis (FEA). The geometry of the designed 4-ENF bonded GFRP specimen [shown in Figure 1] is set as follows: the section size of the GFRP beam is $b \times h=40 \times 4 \mathrm{~mm}$; the span of the GFRP beam is $L=260 \mathrm{~mm}$. The two GFRP beams are bonded together using $1 \mathrm{~mm}$ thick epoxy resin, and the prefabricated crack of length $a$ is located at the end of the bonded beam. The material properties of the GFRP laminates are as follows: $E_{x}=34.9 \mathrm{GPa} ; E_{y}=7.29 \mathrm{GPa} ; v_{x y}=0.258 ; G_{x y}=3.92 \mathrm{GPa}$. The material properties of the epoxy resin are $E_{a}=1.5 \mathrm{GPa}$; $v_{a}=0.3$.

In numerical analysis, a typical two-dimensional finite element model of the 4-ENF test was undertaken using finite

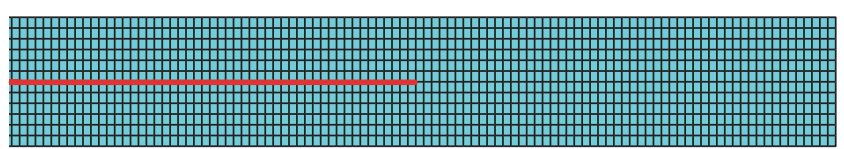

FIGURE 3: Interface mesh of the crack tip area in 4-ENF model.

element software ANSYS. The layered Plane42 element was selected to model the GFRP laminates plate. The prefabricated crack is modelled as a discontinuity element in the middle of the GFRP 4-ENF specimen, setting Targel69 and Conta172 contact elements on the upper and lower contact surfaces of the prefabricated crack zone. The bonded section of the upper and lower beams is set as a Combin14 spring element. Considering that there exists contact phenomena between the upper and lower surfaces of the prefabricated crack, the elements near the crack tip are divided into $0.2 h$, as suggested in [4], where $h$ is the thickness of beam. Since the number of finite elements is so large that the refined meshing sizes are only seen with difficulty in the GFRP 4ENF specimen numerical model, only a typical FE mesh characteristic near the crack tip is shown in Figure 3, in which the red line denotes the crack.

The relational value of the compliances for the 4-ENF specimens with the crack length calculated by different methods (i.e., CBT, rigid joint model, and FEA) is shown in Figure 4(a). The linear curve of the compliance crack length can be observed for the bonded 4-ENF specimen. From Figure 4(a), we can see that the compliance is larger than the rigid joint model and CBT. Moreover, the rigid joint model undervalues the compliance because it ignores the deformation of the adhesive layer. By taking account into the adhesive layer deformation, the present model gives a compliance value closer to the FEA results, which indicates that the adhesive layer deformation is another important factor in contributing to the compliance of 4-ENF specimen. The energy release rate $G_{\text {II }}$ of the adhesive joint crack front can be calculated using the VCCT [23] in FEA. The variation of ERR with regard to the crack length adopted by CBT, the rigid joint model, and FEA is shown in Figure 4(b). As shown in Figure 4(b), the ERR based on all models is a constant value, which is independent of crack length. What is more, the calculated ERR is in good agreement with the FEA result, with a difference of $3.3 \%$, which shows that the current theoretical model is accurate and reasonable.

\section{The GFRP-GFRP Bonded Interface Fracture Toughness by Four-Point Bending Test}

While many studies on the interfacial delamination fracture toughness of FRP material have been conducted, there are few studies on the interfacial fracture toughness for FRP bonded specimens with an adhesive layer. However, the related research shows that the bond performance has an influence on the whole performance and on local failure behavior of the adhesive structure [20,21]. As bond interface crack propagation is different from delamination, the crack propagation of the bonded specimens is unstable. To measure 


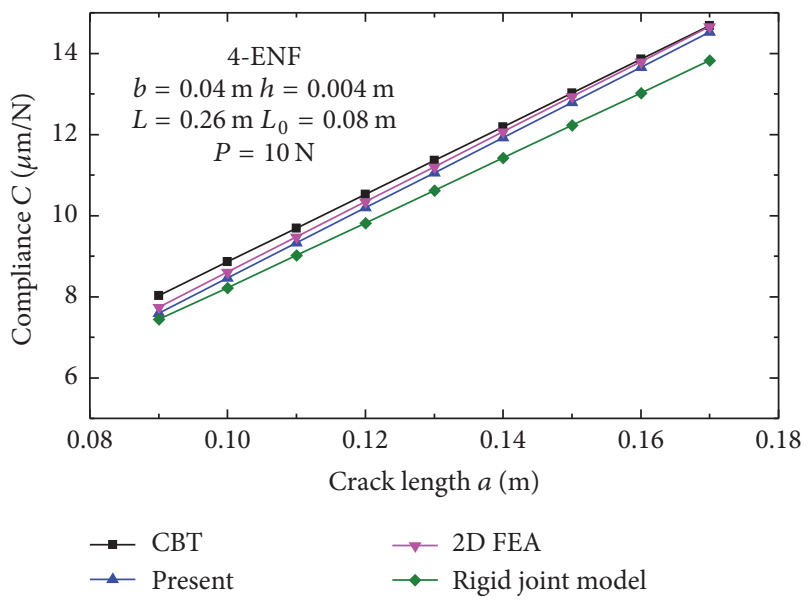

(a)

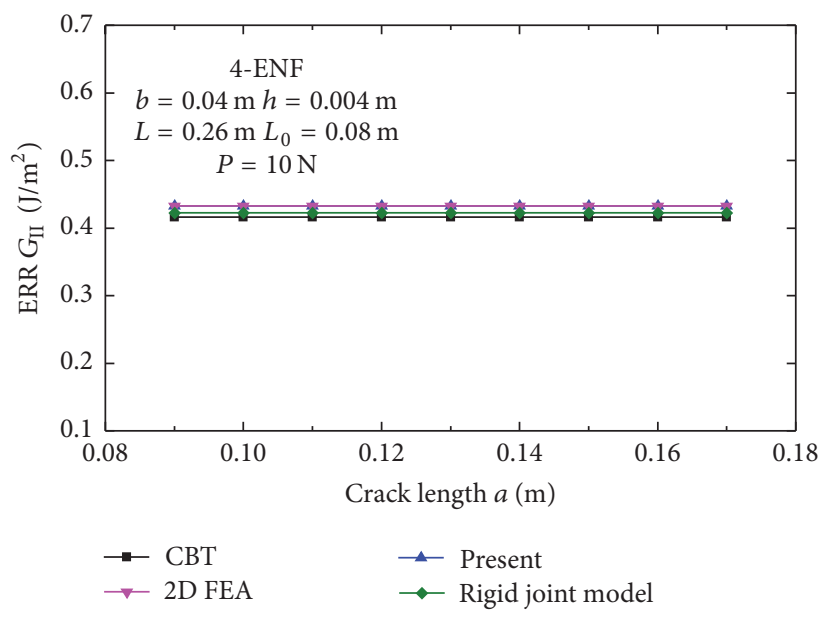

(b)

FIGURE 4: Typical compliance and ERR evaluated as a function of crack length for 4-ENF: (a) compliance; (b) ERR.

TABLE 1: Mechanical properties of pultruded GFRP composite and adhesive layer.

\begin{tabular}{lcccc}
\hline Material name & $E_{x}(\mathrm{GPa})$ & $E_{y}(\mathrm{GPa})$ & $v_{x y}$ & $G_{x y}(\mathrm{GPa})$ \\
\hline GFRP composite & 34.9 & 7.29 & 0.29 & 3.92 \\
Adhesive layer & 1.5 & 1.5 & 0.30 & 0.58 \\
\hline
\end{tabular}

the bonded interfacial fracture toughness accurately, the fabrication of the 4-ENF specimens mentioned in the previous section is used to study the GFRP-GFRP bonded interface. The 4-ENF specimens are made of pultruded GFRP laminate bonded by a $1 \mathrm{~mm}$ thick adhesive layer with a crack length $a$ at the end of the bonded beam. Equal amounts of epoxy resin and curing agent were used in the adhesive layer. The material mechanical properties of pultruded GFRP and adhesive are obtained from ASTM [24-26], as shown in Table 1. The geometry of the designed 4-ENF bonded GFRP specimen is $L=260 \mathrm{~mm} ; b \times h=40 \times 4 \mathrm{~mm}$. The length of the precrack is $150 \mathrm{~mm}$. The fracture test is performed on a material testing system (MTS) servohydraulic testing machine [see Figure 5(a)]. The loading schematic diagram is shown in Figure 5(b). The experiment was performed adopting the displacement control with a loading speed $0.5 \mathrm{~mm} / \mathrm{min}$.

During the experiment, the load-displacement information is continuously and automatically saved by the MTS machine. A typical load-displacement curve for the 4-ENF bonded specimen interfacial fracture is shown in Figure 6. Initially, the displacement increases linearly as the applied load increases. Meanwhile, the elastic strain energy is accumulating in the bonded specimen. When the strain energy increases to the critical value, the crack extension occurs and the elastic strain energy is released. After that, the applied load is decreased, and the propagation of the crack is arrested.

Based on the load-deflection curve, the compliances for the 4-ENF specimens were obtained, and the critical ERR were calculated by applying the critical loads and the compliance rate change $d C / d a$ accordingly. Table 2 summarizes a group of experimental data. For each specimen the value of the critical energy release rate $G_{\text {IIc }}$ was calculated by (26) or VCCT [23] using the crack initiation critical load. An average value of $365.46 \mathrm{~J} / \mathrm{m}^{2}$ was obtained with the coefficient of variation being $19.8 \%$, which is reasonable for bonded composite material. Therefore, it can be observed that $G_{\text {IIc }}$ for the GFRP 4-ENF laminates specimens is determined to be $365.46 \mathrm{~J} / \mathrm{m}^{2}$.

To validate the fracture energy of the interfacial crack determined in the experiment, a numerical simulation of the whole bonded interfacial crack growth process is carried out. Based on the determined average value of $G_{\text {IIc }}\left(G_{\text {IIc }}=\right.$ $365.46 \mathrm{~J} / \mathrm{m}^{2}$ ) shown in Table 2, the whole interfacial crack propagation process is simulated using the VCCT $[23,27]$. When the working ERR in the crack tip satisfies the fracture criterion $G_{\text {II }} \geq G_{\text {IIc }}$, the interfacial crack starts to grow. The comparison between the experimental result and numerical prediction for both load-deflection curves ( $P$ versus $w$ ) is shown in Figure 7. It is clear that the displacement for the load point in the experiment is consistent with the finite element predicted value, which indicated that the previously determined fracture toughness by (26) is true.

\section{Conclusions}

In this study, a beam model including the effect of the adhesive layer deformation is presented to calculate the mode II energy release rate $G_{\text {II }}$ of GFRP bonded four-point bending end-notched flexure (4-ENF) specimens for fracture.

(1) The analytical formula of compliance and ERR based on the crack compliance method for 4-ENF are obtained. According to the model, a linear relation between the average compliance and the crack length is found for the bonded 4-ENF specimens.

(2) The accuracy of the analytical solutions for both the compliance and ERR are verified by finite element analysis through the GFRP bonded interface 


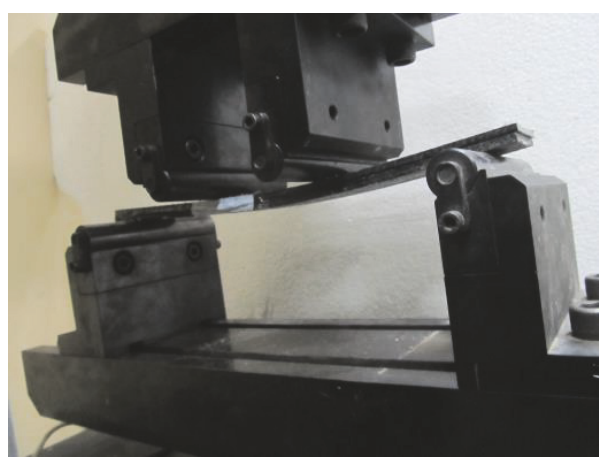

(a)

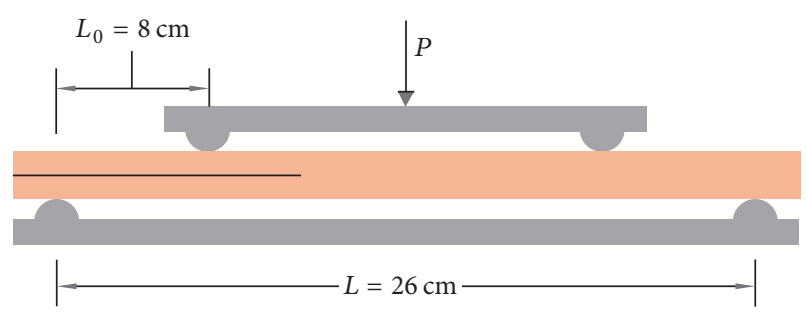

(b)

FIGURE 5: Testing configuration: (a) MTS apparatus; (b) schematic diagram for 4-ENF test.

TABLE 2: Results of critical load $P_{c}$ and fracture toughness $G_{\text {IIc }}$.

\begin{tabular}{lcccc}
\hline Specimen & Critical load $P_{c}(\mathrm{~N})$ & $G_{\text {IIc }}$ calculated by Eq. $(26)\left(\mathrm{J} / \mathrm{m}^{2}\right)$ & $G_{\text {IIc }}$ obtained from VCCT $\left(\mathrm{J} / \mathrm{m}^{2}\right)$ & Error $(\%)$ \\
\hline 1 & 570.00 & 337.90 & 349.43 & 302.65 \\
2 & 612.00 & 389.53 & 378.11 & 3.26 \\
3 & 593.00 & 365.71 & 276.63 & 3.28 \\
4 & 507.00 & 267.33 & 482.30 & 3.36 \\
5 & 670.00 & 466.86 & 377.82 & 3.20 \\
Average & 590.40 & 365.46 & 19.89 & 3.38 \\
COV (\%) & 10.09 & 19.94 & & \\
\hline
\end{tabular}

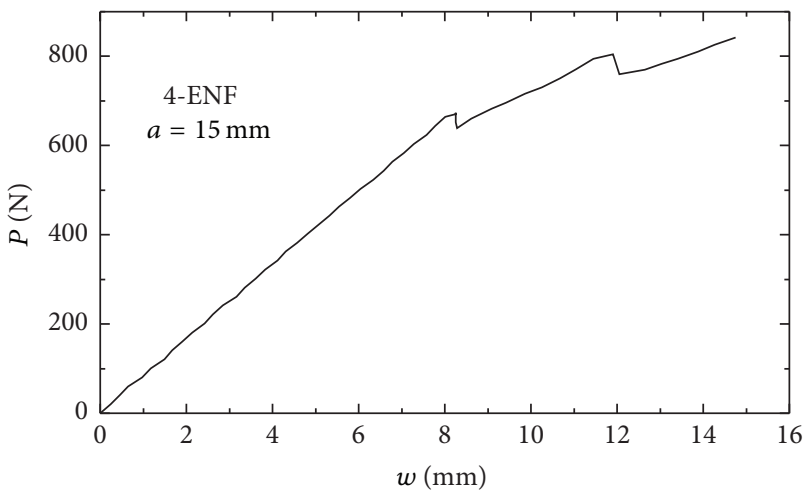

FIGURE 6: Typical load-displacement curve for 4-ENF GFRP bonded specimens.

specimen when compared to the rigid joint model and the CBT model. The compliance and ERR of the present model are closely related to the results obtained by the finite element analysis, demonstrating that the present model is accurately evaluating the compliance and ERR of the four-point bending fracture test.

(3) The interfacial crack propagation is numerically simulated using fracture toughness $G_{\text {IIc }}$ determined in the experiment, by which the predicted $P_{c}$ is in good agreement with the experimental results.

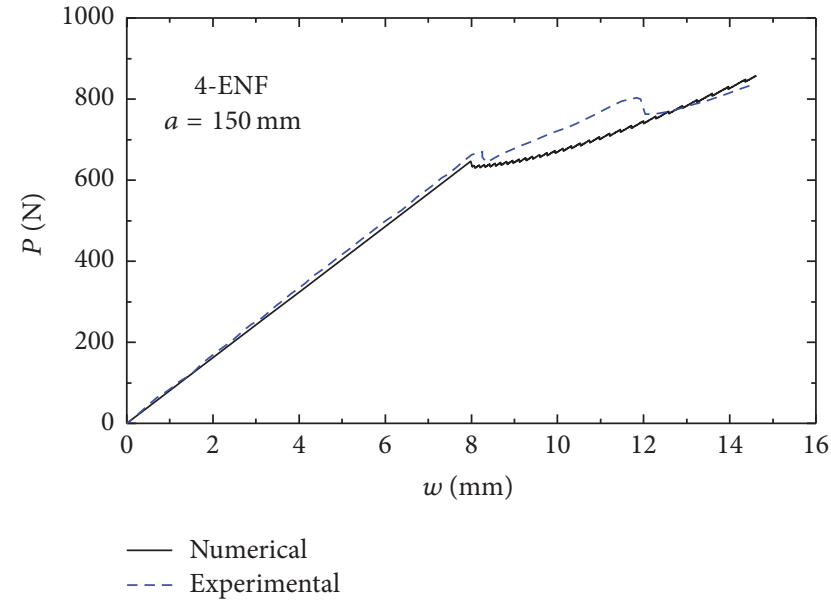

FIGURE 7: Comparison of numerical solution and experimental result for crack growth.

The results obtained from both the theoretical model method and corresponding finite element analysis indicate that the compliance is linearly correlated with crack length and that the calculation of the ERR does not require measuring crack length propagation in the experiment for the bonded 4-ENF beam. By considering adhesive deformation, the present model can calculate the compliance and estimate ERR accurately without knowing the crack length for the bonded 4-ENF beam. 


\section{Appendix}

\section{Coefficient of Adhesively Bonded \\ GFRP 4-ENF Model}

$$
\begin{aligned}
& B_{1}=P\left[\left(D_{1} S L_{0}+D \alpha+D S a \alpha-D S \alpha L\right) e^{-S a}\right. \\
& \left.-\left(D_{1} S L_{0}+D \alpha\right) e^{-S L}\right] \\
& \cdot\left(D D _ { 1 } S ^ { 3 } \left[2\left(e^{S(a-L)}+e^{-S(a-L)}\right)\right.\right. \\
& \left.\left.+\left(e^{-S(a-L)}-e^{S(a-L)}\right)(S a-S L)-4\right]\right)^{-1} \\
& B_{2}=P\left[\left(D_{1} S L_{0}-D \alpha+D S a \alpha-D S \alpha L\right) e^{S a}\right. \\
& \left.-\left(D_{1} S L_{0}-D \alpha\right) e^{S L}\right] \\
& \cdot\left(D D _ { 1 } S ^ { 3 } \left[2\left(e^{S(a-L)}+e^{-S(a-L)}\right)\right.\right. \\
& \left.\left.+(S L-S a)\left(e^{S(a-L)}-e^{-S(a-L)}\right)-4\right]\right)^{-1} \\
& B_{3}=-P\left[\left(D_{1} S L_{0}+D \alpha\right) e^{S(a-L)}+\left(D \alpha-D_{1} S L_{0}\right)\right. \\
& \left.\cdot e^{-S(a-L)}-2 D \alpha\right] \\
& \cdot\left(6 D D _ { 1 } \left[(S a-S L)\left(e^{S(a-L)}-e^{-S(a-L)}\right)\right.\right. \\
& \left.\left.-2\left(e^{S(a-L)}+e^{-S(a-L)}\right)+4\right]\right)^{-1} \\
& B_{4}=-P\left[\left(D_{1} L L_{0} S^{2}+D_{1} S L_{0}-D \alpha+D a \alpha S\right) e^{S(a-L)}\right. \\
& +\left(D_{1} S L_{0}+D \alpha+D S a \alpha-D_{1} L L_{0} S^{2}\right) e^{-S(a-L)} \\
& \left.-2 D_{1} S L_{0}-2 D S \alpha L\right] \\
& \cdot\left(2 D D _ { 1 } S \left[2\left(e^{S(a-L)}+e^{-S(a-L)}\right)\right.\right. \\
& \left.\left.+(S L-S a)\left(e^{S(a-L)}-e^{-S(a-L)}\right)-4\right]\right)^{-1}
\end{aligned}
$$$$
B_{5}=-P\left[( e ^ { S ( a - L ) } + e ^ { - S ( a - L ) } ) \left(6 D S^{2} a^{2} \alpha L_{0}\right.\right.
$$$$
-3 D_{1} S^{2} a^{2} L_{0}-3 D_{1} S^{2} L^{2} L_{0}-3 D S^{2} a \alpha L^{2}
$$$$
-2 D S^{2} \alpha L_{0}^{3}+12 D_{1} L_{0}-D S^{2} a^{3} \alpha-6 D \alpha L
$$$$
\left.+D S^{2} \alpha L^{3}\right)+\left(e^{S(a-L)}-e^{-S(a-L)}\right)\left(D S^{3} a \alpha L_{0}^{3}\right.
$$$$
-3 D_{1} S^{3} a^{2} L L_{0}-3 D S^{3} a^{3} \alpha L_{0}-2 D_{1} S^{3} L^{3} L_{0}
$$$$
+2 D_{1} S^{3} a^{3} L_{0}-D S^{3} \alpha L L_{0}^{3}+3 D S^{3} a^{2} \alpha L L_{0}
$$$$
\left.+3 D S \alpha L^{2}-6 D_{1} S a L_{0}+3 D S a^{2} \alpha\right)+6 D_{1} S^{2} a^{2} L_{0}
$$$$
+6 D S^{2} a^{2} \alpha L+6 D_{1} S^{2} L^{2} L_{0}+4 D S^{2} \alpha L^{3}
$$$$
+4 D S^{2} \alpha L_{0}^{3}-4 D S^{2} a^{3} \alpha+12 D \alpha L-12 D S^{2} a^{2} \alpha L_{0}
$$$$
\left.-24 D_{1} L_{0}\right]
$$

$$
\begin{aligned}
& \cdot\left(6 D D _ { 1 } S ^ { 2 } L \left[(S L-S a)\left(e^{S(a-L)}-e^{-S(a-L)}\right)\right.\right. \\
& \left.\left.+2\left(e^{S(a-L)}+e^{-S(a-L)}\right)-4\right]\right)^{-1} \\
& B_{6}=P\left[( e ^ { S ( a - L ) } + e ^ { - S ( a - L ) } ) \left(6 D_{1} S L_{0}-6 D S a \alpha\right.\right. \\
& +6 D S^{3} a^{2} \alpha L_{0}-3 D_{1} S^{3} a^{2} L_{0}-D S^{3} a^{3} \alpha \\
& \left.-2 D S^{3} \alpha L_{0}^{3}\right)+\left(e^{S(a-L)}-e^{-S(a-L)}\right)\left(3 D S^{2} a^{2} \alpha\right. \\
& +6 D \alpha-D S^{4} \alpha L L_{0}^{3}+3 D S^{4} a^{2} \alpha L L_{0}-3 D S^{4} a^{3} \alpha L_{0} \\
& -3 D_{1} S^{4} a^{2} L L_{0}+D S^{4} a \alpha L_{0}^{3}+2 D_{1} S^{4} a^{3} L_{0} \\
& \left.-6 D_{1} S^{2} a L_{0}\right)+12 D S \alpha L-12 D S^{3} a^{2} \alpha L_{0} \\
& +4 D S^{3} \alpha L_{0}^{3}-4 D S^{3} a^{3} \alpha-12 D_{1} S L_{0}+6 D S^{3} a^{2} \alpha L \\
& \left.+6 D_{1} S^{3} a^{2} L_{0}\right] \\
& \cdot\left(6 D D _ { 1 } S ^ { 3 } \left[(S L-S a)\left(e^{S(a-L)}-e^{-S(a-L)}\right)\right.\right. \\
& \left.\left.+2\left(e^{S(a-L)}+e^{-S(a-L)}\right)-4\right]\right)^{-1} \\
& C_{1}=-P\left[( e ^ { S ( a - L ) } + e ^ { - S ( a - L ) } ) \left(-12 D S^{2} a \alpha L L_{0}\right.\right. \\
& -3 D_{1} S^{2} L^{2} L_{0}+12 D_{1} L_{0}+6 D S^{2} \alpha L L_{0}^{2} \\
& +6 D S^{2} a^{2} \alpha L_{0}-3 D_{1} S^{2} a^{2} L_{0}-D S^{2} a^{3} \alpha \\
& +3 D S^{2} a^{2} \alpha L+D S^{2} \alpha L^{3}-2 D S^{2} \alpha L_{0}^{3}-3 D S^{2} a \alpha L^{2} \\
& \left.+6 D_{1} S^{2} a L L_{0}\right)+\left(e^{S(a-L)}-e^{-S(a-L)}\right) \\
& \text {. }\left(9 D S^{3} a^{2} \alpha L L_{0}-6 D_{1} S a L_{0}-6 D_{1} S^{3} a^{2} L L_{0}\right. \\
& +3 D S \alpha L^{2}+D S^{3} a \alpha L_{0}^{3}+6 D_{1} S L L_{0} \\
& +6 D_{1} S^{3} a L^{2} L_{0}-6 D S a \alpha L-6 D S^{3} a \alpha L^{2} L_{0} \\
& -3 D S^{3} a^{3} \alpha L_{0}+2 D_{1} S^{3} a^{3} L_{0}+3 D S a^{2} \alpha \\
& -3 D S^{3} a \alpha L L_{0}^{2}+3 D S^{3} \alpha L^{2} L_{0}^{2}-2 D_{1} S^{3} L^{3} L_{0} \\
& \left.-D S^{3} \alpha L L_{0}^{3}\right)-12 D S^{2} a \alpha L^{2}-24 D_{1} L_{0} \\
& +24 D S^{2} a \alpha L L_{0}+6 D_{1} S^{2} a^{2} L_{0}+4 D S^{2} \alpha L_{0}^{3} \\
& -12 D S^{2} \alpha L L_{0}^{2}+12 D S^{2} a^{2} \alpha L-12 D_{1} S^{2} a L L_{0} \\
& +6 D_{1} S^{2} L^{2} L_{0}-4 D S^{2} a^{3} \alpha-12 S^{2} a^{2} D \alpha L_{0} \\
& \left.+4 D S^{2} \alpha L^{3}\right] \\
& \cdot\left(6 D D _ { 1 } S ^ { 2 } L \left[(S L-S a)\left(e^{S(a-L)}-e^{-S(a-L)}\right)\right.\right. \\
& \left.\left.+2\left(e^{S(a-L)}+e^{-S(a-L)}\right)-4\right]\right)^{-1} \\
& C_{2}=0
\end{aligned}
$$




$$
\begin{aligned}
& C_{3}=-P\left[( e ^ { S ( a - L ) } + e ^ { - S ( a - L ) } ) \left(12 D_{1} L_{0}-3 D_{1} S^{2} a^{2} L_{0}\right.\right. \\
& -12 D S^{2} a \alpha L L_{0}-3 D S^{2} a \alpha L^{2}+6 D S^{2} a^{2} \alpha L_{0} \\
& -2 D S^{2} \alpha L_{0}^{3}+3 D S^{2} a^{2} \alpha L+6 D_{1} S^{2} a L L_{0}-D S^{2} a^{3} \alpha \\
& \left.-3 D_{1} S^{2} L^{2} L_{0}+D S^{2} \alpha L^{3}\right)+\left(e^{S(a-L)}-e^{-S(a-L)}\right) \\
& \cdot\left(6 D_{1} S L L_{0}+2 D_{1} S^{3} a^{3} L_{0}-6 D S a \alpha L\right. \\
& +9 D S^{3} a^{2} \alpha L L_{0}-2 D_{1} S^{3} L^{3} L_{0}+3 D S \alpha L^{2} \\
& +6 D_{1} S^{3} a L^{2} L_{0}-3 D S^{3} a^{3} \alpha L_{0}-6 D S^{3} a \alpha L^{2} L_{0} \\
& -6 D_{1} S^{3} a^{2} L L_{0}-6 D_{1} S a L_{0}+3 D S a^{2} \alpha \\
& \left.+D S^{3} a \alpha L_{0}^{3}-D S^{3} \alpha L L_{0}^{3}\right)+6 D_{1} S^{2} L^{2} L_{0} \\
& +6 D_{1} S^{2} a^{2} L_{0}-12 D S^{2} a \alpha L^{2}-24 D_{1} L_{0} \\
& +4 D S^{2} \alpha L_{0}^{3}+4 D S^{2} \alpha L^{3}-4 D S^{2} a^{3} \alpha \\
& -12 D S^{2} a^{2} \alpha L_{0}-12 D_{1} S^{2} a L L_{0}+24 D S^{2} a \alpha L L_{0} \\
& \left.+12 D S^{2} a^{2} \alpha L\right] \\
& \cdot\left(6 D D _ { 1 } S ^ { 2 } L \left[(S L-S a)\left(e^{S(a-L)}-e^{-S(a-L)}\right)\right.\right. \\
& \left.\left.+2\left(e^{S(a-L)}+e^{-S(a-L)}\right)-4\right]\right)^{-1} \\
& C_{4}=-\frac{\alpha P L_{0}^{3}}{6 D_{1}} \\
& F_{0}=\left(6 D S \alpha L_{0}-6 D_{1} S^{3} L L_{0}^{2}-6 D S \alpha L+3 D S^{3} \alpha L^{2} L_{0}\right. \\
& \left.-3 D S^{3} \alpha L L_{0}^{2}+3 D_{1} S^{3} L_{0}^{3}+6 D_{1} S L_{0}+9 D S^{3} \alpha L_{0}^{3}\right) \\
& -\left(D_{1} S^{4} L_{0}^{4}-3 D_{1} S^{4} L^{2} L_{0}^{2}+6 D S^{2} \alpha L L_{0}\right. \\
& \left.-3 D S^{2} \alpha L_{0}^{2}-6 D \alpha+6 D_{1} S^{2} L_{0}^{2}+4 D S^{4} \alpha L L_{0}^{3}\right)
\end{aligned}
$$

\section{Conflicts of Interest}

The authors declare that they have no conflicts of interest.

\section{Acknowledgments}

The work is supported by the National Basic Research Program (973) of China (no. 2012CB026200), the Fundamental Research Funds for the Central Universities (126545010), and the Southeast University, Key Laboratory of Concrete and Prestressed Concrete Structure of Ministry of Education (CPCSME2015-03).

\section{References}

[1] C. E. Bakis, L. C. Bank, V. L. Brown et al., "Fibre-reinforced polymer composites for construction, state-of-the-Art Review,"
Journal of Composites for Construction, vol. 6, no. 2, pp. 73-87, 2002.

[2] R. M. W. Reising, B. M. Shahrooz, V. J. Hunt, A. R. Neumann, A. J. Helmicki, and M. Hastak, "Close look at construction issues and performance of four fiber-reinforced polymer composite bridge decks," Journal of Composites for Construction, vol. 8, no. 1, pp. 33-42, 2004.

[3] A. Zhou and T. Keller, "Joining techniques for fiber reinforced polymer composite bridge deck systems," Composite Structures, vol. 69, no. 3, pp. 336-345, 2005.

[4] Z. Jiang, S. Wan, Z. Zhong, M. Li, and K. Shen, "Determination of mode-I fracture toughness and non-uniformity for GFRP double cantilever beam specimens with an adhesive layer," Engineering Fracture Mechanics, vol. 128, pp. 139-156, 2014.

[5] C. R. Corleto and H. A. Hogan, "Energy Release Rates for the ENF Specimen Using a Beam on an Elastic Foundation," Journal of Composite Materials, vol. 29, no. 11, pp. 1420-1436, 1995.

[6] R. H. Martin and B. D. Davidson, "Mode II fracture toughness evaluation using four point bend, end notched flexure test," Plastics, Rubber and Composites, vol. 28, no. 8, pp. 401-406, 1999.

[7] C. Schuecker and B. D. Davidson, "Evaluation of the accuracy of the four-point bend end-notched flexure test for mode II delamination toughness determination," Composites Science and Technology, vol. 60, no. 11, pp. 2137-2146, 2000.

[8] S. Hashemi, A. J. Kinloch, and J. G. Williams, "Mechanics and mechanisms of delamination in a poly(ether sulphone)-fibre composite," Composites Science and Technology, vol. 37, no. 4, pp. 429-462, 1990.

[9] H. Wang and T. Vu-Khanh, "Use of end-loaded-split (ELS) test to study stable fracture behaviour of composites under mode II loading," Composite Structures, vol. 36, no. 1-2, pp. 71-79, 1996.

[10] A. Szekrényes and J. Uj, "Beam and finite element analysis of quasi-unidirectional composite SLB and ELS specimens," Composites Science and Technology, vol. 64, no. 15, pp. 23932406, 2004.

[11] A. Szekrényes and J. Uj, "Mode-II fracture in E-glass-polyester composite," Journal of Composite Materials, vol. 39, no. 19, pp. 1747-1768, 2005.

[12] K. Tanaka, T. Yuasa, and K. Katsura, "Continuous mode II interlaminar fracture toughness measurement by over notched flexure test," in Proceedings of the 4th European Conference on Composites: Testing and Standardisation, pp. 171-179, Lisbon, Portugal, 1998.

[13] A. Szekrényes, "Crack stability of fracture specimens used to test unidirectional fiber reinforced material," Experimental Mechanics, vol. 50, no. 4, pp. 473-482, 2010.

[14] A. J. Russell and K. N. Street, "Factors affecting the interlaminar fracture energy of graphite/epoxy laminates," Progress in Science and Engineering of Composites, pp. 279-286, 1982.

[15] L. A. Carlsson, J. W. Gillespie Jr., and R. B. Pipes, "On the analysis and design of the end notched flexure (ENF) specimen for mode II testing," Journal of Composite Materials, vol. 20, no. 6, pp. 594-604, 1986.

[16] J. M. Whitney and C. T. Sun, "A higher order theory for extensional motion of laminated composites," Journal of Sound and Vibration, vol. 30, no. 1, pp. 85-97, 1973.

[17] Y. Wang and J. G. Williams, "Corrections for mode II fracture toughness specimens of composites materials," Composites Science and Technology, vol. 43, no. 3, pp. 251-256, 1992.

[18] W. Ding and M. T. Kortschot, "A simplified beam analysis of the end notched flexure mode II delamination specimen," Composite Structures, vol. 45, no. 4, pp. 271-278, 1999. 
[19] J. Wang and P. Qiao, "Novel beam analysis of end notched flexure specimen for mode-II fracture," Engineering Fracture Mechanics, vol. 71, no. 2, pp. 219-231, 2004.

[20] T. Keller and H. Gürtler, "Composite action and adhesive bond between fiber-reinforced polymer bridge decks and main girders," Journal of Composites for Construction, vol. 9, no. 4, pp. 360-368, 2005.

[21] Y. Zhang, A. P. Vassilopoulos, and T. Keller, "Mode I and II fracture behavior of adhesively-bonded pultruded composite joints," Engineering Fracture Mechanics, vol. 77, no. 1, pp. 128143, 2010.

[22] K. Kageyama, "Composite Materials: Fatigue and Fracture (Third Volume)," Tech. Rep. ASTM STP 1110, ASTM International, West Conshohocken, PA, USA, 1991.

[23] D. Xie and S. B. Biggers Jr., "Progressive crack growth analysis using interface element based on the virtual crack closure technique," Finite Elements in Analysis and Design, vol. 42, no. 11, pp. 977-984, 2006.

[24] ASTM D3039/D3039M-14, "Standard test method for tensile properties of polymer matrix composite materials," Tech. Rep., American Society for Testing Materials, West Conshohocken, PA, USA, 2014.

[25] ASTM, "Standard test method for flexural properties of unreinforced and reinforced plastics and electrical insulating materials by four-point bending," ASTM Standard D6272, American Society for Testing Materials, West Conshohocken, PA, USA, 2010.

[26] China NSOT, GB/T 2567-2008 Test Methods for Properties of Resin Casting Body, China Standard Press, Beijing, China, 2008.

[27] D. Xie and S. B. Biggers Jr., "Strain energy release rate calculation for a moving delamination front of arbitrary shape based on the virtual crack closure technique. Part I: formulation and validation," Engineering Fracture Mechanics, vol. 73, no. 6, pp. 771-785, 2006. 

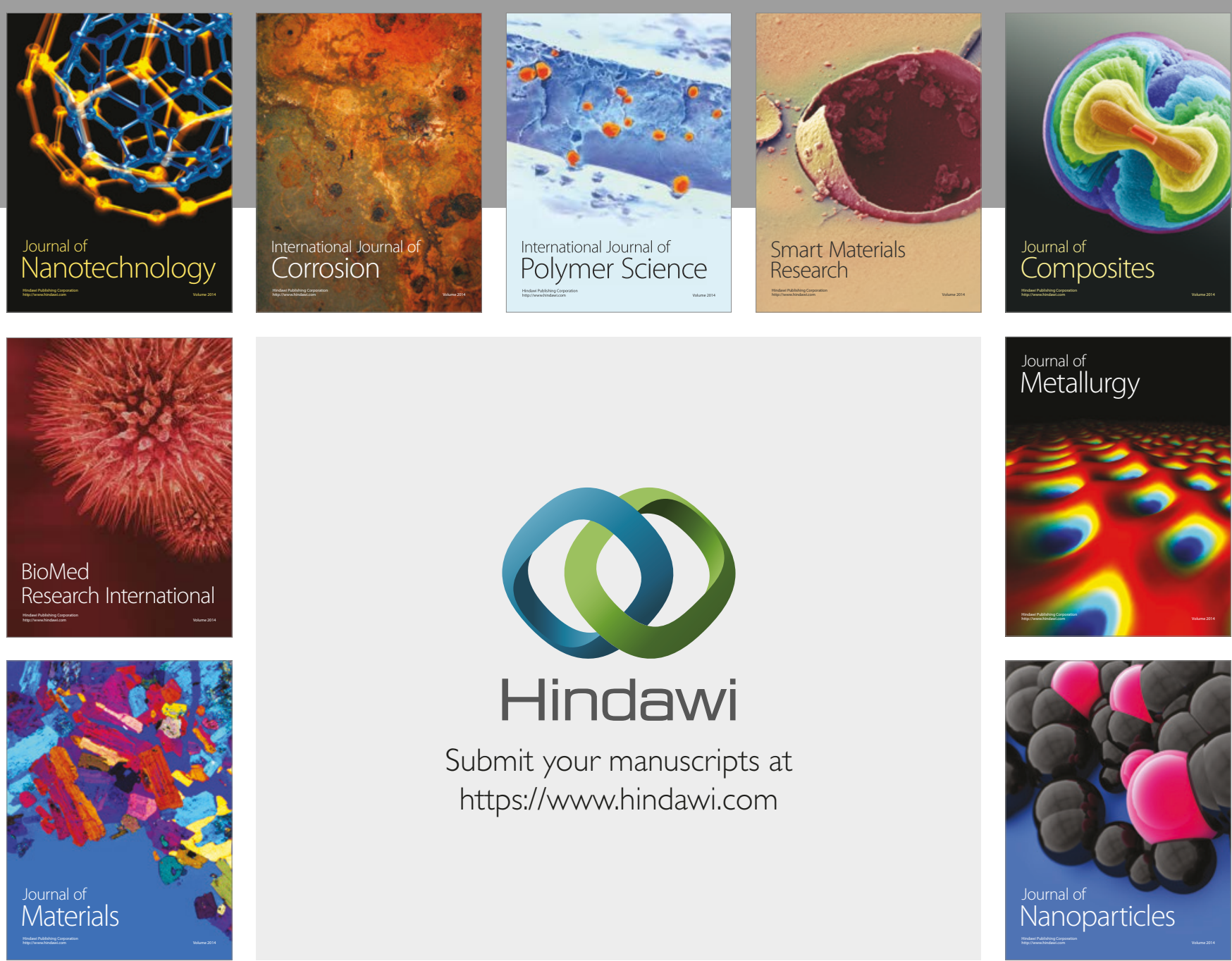

\section{Hindawi}

Submit your manuscripts at

https://www.hindawi.com
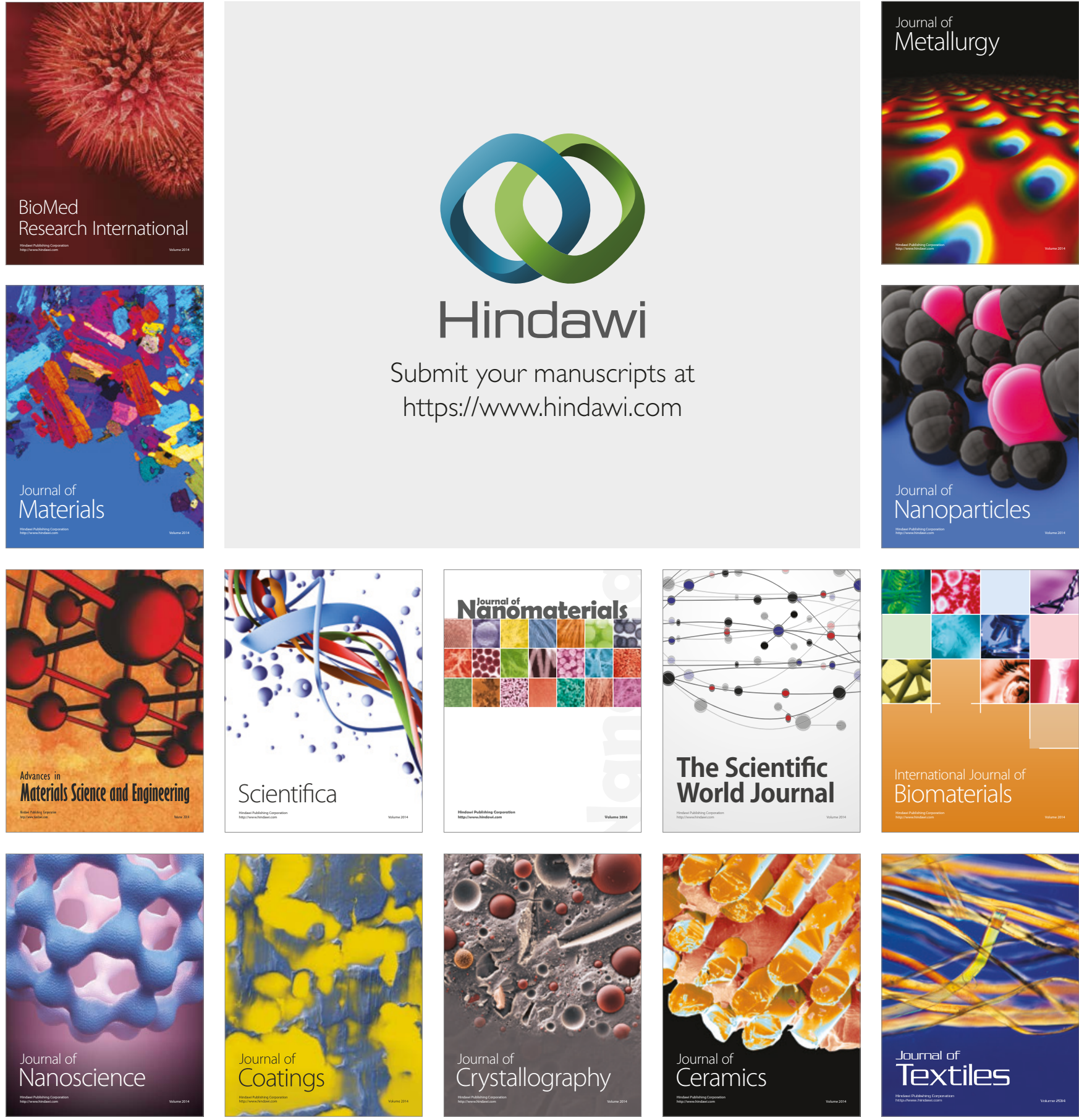

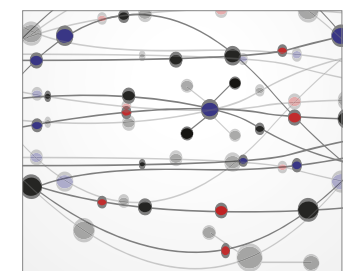

The Scientific World Journal
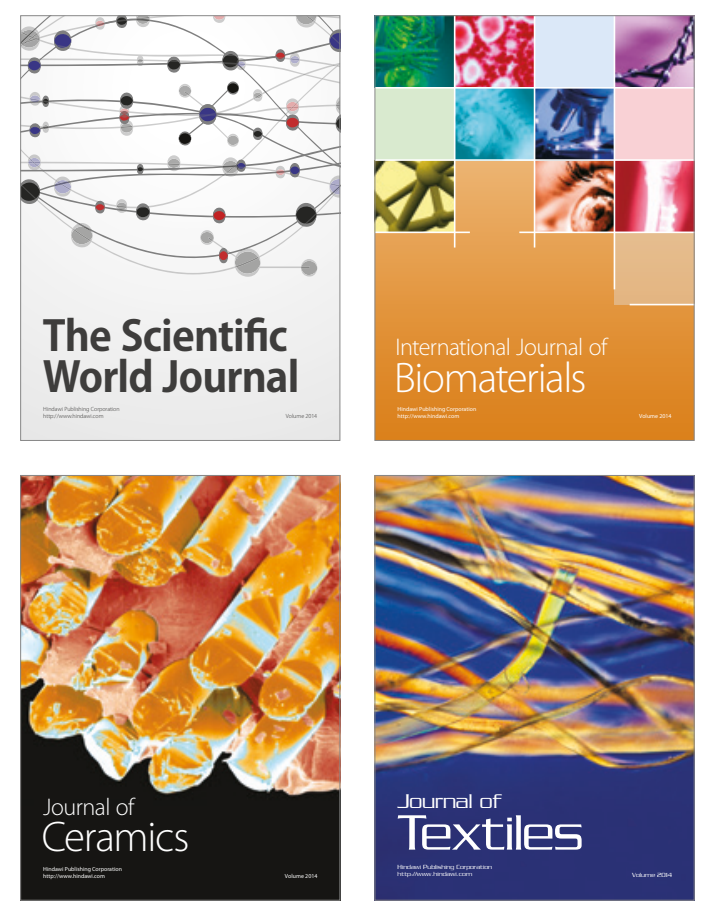